\title{
Icariin Enhances Bone Repair in Rabbits with Bone Infection during Post-infection Treatment and Prevents Inhibition of Osteoblasts by Vancomycin
}

\author{
Yang Zhang ${ }^{1 t}$, Lifeng Shen ${ }^{2 t}$, Zhujun Mao', Nani Wang', Xuping Wang', \\ Xiaowen Huang ${ }^{1}$, Ying $\mathrm{Hu}^{3}$, Dan Shou ${ }^{1 *}$ and Chengping Wen ${ }^{4 *}$ \\ ${ }^{1}$ Department of Medicine, Zhejiang Academy of Traditional Chinese Medicine, Hangzhou, China, ${ }^{2}$ Department of \\ Orthopaedic Surgery, Zhejiang Provincial Tongde Hospital, Hangzhou, China, ${ }^{3}$ Zhejiang Pharmaceutical College, Ningbo, \\ China, ${ }^{4}$ College of Basic Medicine, Zhejiang Chinese Medical University, Hangzhou, China
}

\section{OPEN ACCESS}

Edited by:

Victor Kuete,

University of Dschang, Cameroon

Reviewed by:

Wei Zhang,

Macau University of Science and Technology, China Johanna Mahwahwatse Bapela, University of Pretoria, South Africa

${ }^{*}$ Correspondence:

Dan Shou

shoudanok@163.com

Chengping Wen

wengcp@163.com

${ }^{\dagger}$ These authors have contributed equally to this work.

Specialty section:

This article was submitted to

Ethnopharmacology,

a section of the journal

Frontiers in Pharmacology

Received: 20 July 2017 Accepted: 16 October 2017 Published: 31 October 2017

Citation: Zhang Y, Shen L, Mao Z, Wang N, Wang $X$, Huang $X, \mathrm{Hu} Y$, Shou D and Wen $C$ (2017) Icariin Enhances

Bone Repair in Rabbits with Bone Infection during Post-infection Treatment and Prevents Inhibition of Osteoblasts by Vancomycin.

Front. Pharmacol. 8:784. doi: 10.3389/fphar.2017.00784
Vancomycin is an effective antibiotic for treatment of bone infection caused by Staphylococcus aureus, however, a high local concentration of vancomycin might induce a delay in bone union. Icariin has been reported to suppress osteoclastogenes and promote osteogenesis. Our study aimed to investigate the effect of icariin on bone repair after anti-infection treatment in vivo and to explore the resisting effect of icariin on rat calvarial osteoblasts (ROBs) inhibited with high doses of vancomycin. Rabbits with bone infection of $S$. aureus were treated with implanted vancomycin-calcium sulfate (VCS) and icariin at $10.86 \mathrm{mg} / \mathrm{kg} /$ day for consecutive 8 weeks. Micro-CT, morphology, blood biochemistry were evaluated. In addition, ROBs were treated with vancomycin and icariin at different doses. Cell proliferation and differentiation capabilities, BMP2, Runx2, OPG, RANKL mRNA levels and protein expression were assessed. The results indicated that high dose of vancomycin significantly decreased bone mass and inhibited osteocalcin secretion; icariin increased these indicators compared with the single vancomycin treatment. Over $0.1 \mathrm{mg} / \mathrm{mL}$ of vancomycin inhibited the proliferation and differentiation of ROBs, while icariin resisted the inhibition of vancomycin by regulating cell cycle and promoting the Alkaline phosphatase (ALP) activity. Moreover, icariin promote bone formation by up-regulating BMP2/Runx2 and OPG/RANKL pathways. Icariin exhibited osteoplastic properties on osteoblasts that had been inhibited with high doses of vancomycin. Therefore, icariin is helpful for post-infection treatment of bone infection.

\section{Keywords: icariin, vancomycin, bone infection, post-infection treatment, bone repair}

\footnotetext{
Abbreviations: ALP, alkaline phosphatase; BFR, bone-formation rate; BMD, bone mineral density; BMP, bone morphogenetic protein; B.pm, bone perimeter; BV/TV, ratio of bone volume/tissue volume; CRP, high sensitive C-reactive protein; ELISA, enzyme linked immunosorbent assay; H\&E, hematoxylin and eosin; MAR, mineral appositional rate; MTT, methyl thiazolyl tetrazolium; N.Ob, osteoblast number; OC, osteocalcin; OPG, osteoprotegrin; PI, propidium iodide; RANKL, nuclear factor-kB ligand; ROBs, rat calvarial osteoblasts; ROI, regions of interest; Runx2, runt-related transcription factor 2; S. aureus, Staphylococcus aureus; T.Ar, trabecular bone area; VCS, vancomycin-calcium sulfate; VCS-H, high dose VCS, VCS-L, low dose VCS; WBC, white blood count.
} 


\section{INTRODUCTION}

Many factors contribute to the increase in severe bone infections and tissue suppurations, including accidents and the increased use of orthopedic devices. Bone infection has various impacts on patients, such as delayed unions and amputation (Hassani Besheli et al., 2017). Therefore, the treatment of bone infection remains a critical challenge for many orthopedic surgeons. Bone infection is mostly caused by $S$. aureus, and vancomycin is the main antibiotic that has been shown to effectively control the bone infection in the form of intravenous infusions of vancomycin and local placement of vancomycin loaded delivery vehicles (Farokhi et al., 2016; Hsu et al., 2017; Zhang et al., 2017). Nevertheless, in $10-15 \%$ of cases of bone infection, patients experienced a long bone union process, delayed union or non-union after anti-infection treatment. The factors that lead to delayed union are still unknown; some reports stated that it resulted from inflammation or even a high concentration of antibiotic medication (Eder et al., 2016; Mendoza et al., 2016). Traditionally, the main role of the local placement of VCS is to release vancomycin in the infected marrow cavity and bone to inhibit bacterium and avoid potential infection. However, the local concentrations exceeded minimal inhibitory concentrations by greater than 1000 -fold in patients who received a $100 \mathrm{mg}$ dose of vancomycin (Shou et al., 2014). In fact, a high dose of VCS (more than $1 \mathrm{~g}$ of vancomycin) was usually implanted into the local site to control the repeated infection in some cases. In addition, a previous study indicated that a high concentration of vancomycin (more than $4 \mathrm{mg} / \mathrm{mL}$ ) can decrease the number of osteogenic cells, induce a loss in pseudopodia formation and alter the normal shape of the cytoplasm (Rathbone et al., 2011; Goldschmidt et al., 2016).

Chinese medicinal plants have been reported to possess osteoprotective and related properties in vitro and/or in vivo (Che et al., 2016). Herba Epimedii is commonly used for the treatment of fractures and other bone diseases. In our previous study, the bioactive flavonoids of Herba Epimedii, including icariin and epimedin A, B, and C, promoted bone formation in the rabbit model during post-infection treatment (Shou et al., 2017). Icariin is the major bioactive compound of Herba Epimedii (Jin et al., 2013), and has been shown to suppress osteoclastogenes in ovariectomized mice (Mok et al., 2010; Li et al., 2014), promote osteoblasts differentiation, and inhibit osteoclast differentiation (Zheng et al., 2012; Li et al., 2016).

This study was designed to evaluate the efficacy of icariin in a rabbit model of bone infection treated with VCS and to ascertain its effect on the proliferation of ROBs induced by vancomycin. In addition, the mechanism of the inhibition of vancomycin on ROBs and the reverse effect of icariin were demonstrated by RT-PCR and Western blot. The purpose of the current study was to provide a new remedy from Herba Epimedii to promote healing after a bone infection during the post-infection treatment with vancomycin.

\section{MATERIALS AND METHODS}

\section{Animal Groups and Treatment}

The animal experiments were performed in accordance with the Guide for the Care and Use of Laboratory Animals and were approved by the Bioethics Committee of Zhejiang Academy of Traditional Chinese Medicine. Male New Zealand white rabbits (SCXK 2014-0047), aged 3 months and weighing $3.0 \pm 0.2 \mathrm{~kg}$, were housed in individual cages under air-controlled conditions $\left(20 \pm 1^{\circ} \mathrm{C}\right.$ and $12 \mathrm{~h} / 12 \mathrm{~h}$ light-dark illumination cycles), and offered the same commercial diet and tap water. The model was prepared according to previously established method (Shou et al., 2017). In total, $90 \%$ of the rabbits were diagnosed with bone infection 4 weeks after infection, and five rabbits were killed for microbiological and histological examination. As shown in Table 1, the rabbits in the VCS-H group, the VCS-L group and the VCS-icariin group were subjected to debridement of necrotic tissue by punching two adjacent $4-\mathrm{mm}$ diameter holes in the bone, scraping and cleaning the tissue between the two holes, then implanting VCS beads (doses of vancomycin are shown in Table 1, rabbits in the VCS-H group were implanted $25 \mathrm{mg}$ vancomycin, rabbits in the VCS-L group were implanted $12.5 \mathrm{mg}$ vancomycin) in the holes during the implanting operation. In the VCS-icariin group, rabbits were implanted $25 \mathrm{mg}$ vancomycin, and administered intragastrically with icariin (purity $\geq 98 \%$, purchased from Beijing Aoke Biological Technology, Co., Ltd.) at $10.86 \mathrm{mg} / \mathrm{kg} /$ day once a day, for 8 weeks, the dose was recommended by our previous study. The control and model groups were housed under the same conditions but were not treated.

\section{Evaluation of Anti-infection Action and Bone Formation}

Specimens collected post-mortem from the bone and marrow as well as necrotic tissues collected at the time of debriding were immediately inoculated on blood agar and incubated for at least $48 \mathrm{~h}$ at $37^{\circ} \mathrm{C}$. The identification of $S$. aureus was based on conventional criteria, including the coagulase tube test and the API Staph-Ident system (ATB 32 Staph. BioMerieux, Marcyl'Étoile, France). The inflammatory indexes, such as CRP and WBC in serum were detected. ALP and osteocalcin in blood or tissue were measured by ELISA. ELISA kits were purchased from Beyotime Biotechnology, Co., Ltd., (Shanghai, China), and the absorbance of ALP and OC were detected by Microplate Reader (Bio-Tek, Winooski, VT, United States).

\section{Serum Concentrations of Icariin and Local Concentrations of Vancomycin}

In the VCS-icariin group, blood was drawn from the rabbit's auricular vein at $1,2,6$, and $12 \mathrm{~h}$ after the first administration, and $2 \mathrm{~h}$ after the administration of icariin for $2,3,5,10,15$, 20 , and 30 days. The serum concentrations were determined according to the published method (Wang et al., 2015). Three rabbits in the VCS-L and VCS-H groups at the 2nd, 4th, 6th, 8th, and 15th day after treatment were executed, and the bone marrow was collected and diluted in a constant volume with 
TABLE 1 | Animals, groups, and treatments.

\begin{tabular}{|c|c|c|c|c|c|}
\hline \multirow[t]{2}{*}{ Group } & \multirow[t]{2}{*}{ Number } & \multirow[t]{2}{*}{ Model (M) } & \multicolumn{2}{|c|}{ Treatment (T) } & \multirow[t]{2}{*}{ Euthanasia time point after $\mathbf{M}$ or $\mathbf{T}$} \\
\hline & & & Vancomycin & Icariin & \\
\hline Control & 5 & Infection & None & None & $4 \mathrm{w}$ after $M$ \\
\hline \multirow[t]{2}{*}{ Model } & 5 & Infection & None & None & $4 \mathrm{w}$ after $M$ \\
\hline & 10 & Infection & None & None & $4 w$ and $8 w$ after $T$ \\
\hline VCS-H & 20 & Infection & 25 mg & None & $4 \mathrm{w}$ and $8 \mathrm{w}$ after $\mathrm{T}$ \\
\hline VCS-L & 20 & Infection & $12.5 \mathrm{mg}$ & None & $4 w$ and $8 w$ after $T$ \\
\hline VCS-icariin & 10 & Infection & 25 mg & 10.86 mg/kg/day & $4 w$ and $8 w$ after $T$ \\
\hline
\end{tabular}

normal saline. The local concentrations of vancomycin were determined via a previously established method (Shou et al., 2014).

\section{Micro-CT Analysis}

At the 4th and 8th week, tibia specimens were examined by Micro-CT (SkyScan-1172 micro-CT scanner, Bruker, Switzerland). Oval areas 4-mm in diameter and 8-mm long were chosen as ROI (Suwanprateeb et al., 2014; Dong et al., 2017). A reconstruction of the bitmap data set was obtained and used to build the 3D model. The model was bisected with a mid-sagittal plane. Scores for the BV/TV, and BMD were obtained directly from the $3 \mathrm{D}$ model, following a previously study (Ren et al., 2015).

\section{Histological Analysis}

Double labeling was performed on rabbits before they were euthanized to measure the MAR and the BFR. Calcein $(20 \mathrm{mg} / \mathrm{kg})$, alizarin red $(30 \mathrm{mg} / \mathrm{kg})$, and tetracycline $(30 \mathrm{mg} / \mathrm{kg})$ were injected intraperitoneally at 7, 14, and 21 days before euthanasia, respectively. The dissected tibia samples were fixed in $10 \%$ EDTA for 8 weeks, dehydrated in a graded series of ethanol dilutions, and then embedded in plastic sections. Unstained transverse sections (3 $\mathrm{mm}$ thick) were examined with a fluorescent microscope and the Osteo Measure System (OsteoMetrics, Inc.). The other tibia specimens were fixed in $4 \%$ paraformaldehyde for $24 \mathrm{~h}$, decalcified in $10 \%$ EDTA for 8 weeks, dehydrated in a graded series of ethanol dilutions, and then embedded in paraffin wax. At least four consecutive 5- $\mu \mathrm{m}$ sections were obtained from the coronal planes and subjected to H\&E for morphologic analysis. Transmitted light images of the stained sections were taken with a microscope (Olympus-CX41, Olympus, Japan) connected to a CCD camera (DP72; Olympus, Japan), and the images were recorded with cellSens standard software (Olympus, Japan).

\section{Immunohistochemical Analysis}

Sections were pre-treated and stained for OC (1:100; Abcam, Ltd., Cambridge, United Kingdom) with a previously described method (Bian et al., 2012). A morphometric study was performed with an auto-analysis imaging system (Olympus-CX41, Olympus, Japan). The data were quantified with a medical image management system (Image-Pro Plus, IPP6.0).

\section{ROBs Culture and Treatment}

Rat calvarial osteoblasts were isolated and cultured in a fully humidified incubator $\left(37^{\circ} \mathrm{C}, 5 \% \mathrm{CO}_{2}\right)$ and seeded in 96-well plates at a density of $1 \times 10^{5}$ per well. A total of $100 \mu \mathrm{L}$ of vancomycin $(0.1 \mathrm{mg} / \mathrm{mL})$ and icariin $(0.01,0.02,0.05 \mathrm{mg} / \mathrm{mL})$ were added after the cells had completely adhered.

\section{Evaluation of Cell Proliferation and Differentiation}

Cell proliferation was measured using a standard MTT assay. Prior to the end of the 24 -h culture, $50 \mu \mathrm{L}$ of MTT $(5 \mathrm{mg} / \mathrm{mL})$ was added to each well, incubated for $4 \mathrm{~h}$, then the medium was discarded, and $100 \mu \mathrm{L}$ of DMSO were added to each well. The UV absorbance was measured at $490 \mathrm{~nm}$ on an ELx-808 universal microplate reader (Bio-Tek) as an indicator of cell proliferation. Cell cycle analyses were evaluated by the DNA distribution and examined using propidium iodide (PI) staining (SigmaAldrich). ROBs were harvested after treatment vancomycin and icariin or no treatment (Control cells), fixed in $70 \%$ chilled ethanol, and kept at $-20^{\circ} \mathrm{C}$ for at least $24 \mathrm{~h}$. To measure the DNA contents, the cells were washed twice with PBS, digested with $10 \mathrm{mg} / \mathrm{mL}$ RNaseA (Sigma Aldrich) for $10 \mathrm{~min}$, and then stained with $50 \mathrm{mg} / \mathrm{mL}$ PI. The DNA contents were analyzed using a flow cytometer (Becton Dickinson, Mountain View, CA, United States). ALP is an enzyme expressed by cells, and its activity is a well-defined marker for osteogenesis. ALP is a marker of bone formation and differentiation of osteoblasts. ALP activity was measured according to the literature (Jiao et al., 2009).

\section{Real-time PCR}

Total RNA was extracted from ROBs using TRIzol (Invitrogen Life Technologies, Carlsbad, CA, United States). Reverse transcription was performed with an RT-for-PCR kit (Qiagen, Valencia, CA, United States) following the manufacturer's protocol. Real-time PCR was performed with SYBR Premix Ex Taq (Takara Bio) in an RG3000 machine (Corbett Research, Australia). Target mRNA expression was normalized to $\beta$-actin expression. PCR products were subjected to melt curve analysis, and the data were quantified with Rotor Gene 6.0 analysis software.

\section{Western Blot Analysis}

Proteins from ROBs were extracted with E-PER protein extraction reagents (Thermo Scientific, Waltham, MA, 
United States), transferred onto a PVDF membrane (BioRad, Hercules, CA, United States) blocked with 5\% non-fat milk in PBST at room temperature. After an overnight incubation with the primary antibody at $4^{\circ} \mathrm{C}$ and incubation with the HRPconjugated secondary antibodies (Thermo Scientific, Waltham, MA, United States) at RT, protein expression was detected with a Super Signal West Femto Maximum Sensitivity Substrate Kit (Thermo Scientific, Waltham, MA, United States). The anti-GAPDH polyclonal mouse antibody (Sigma, St. Louis, MO, United States), anti-BMP2 polyclonal rabbit antibody, anti-OPG polyclonal rabbit antibody, and anti-RANKL polyclonal rabbit antibody (Abcam, Cambridge, MA, United States) served as primary antibodies.

\section{Statistical Analysis}

The data are presented as the mean $\pm \mathrm{SD}$, and statistical significance was calculated via one-way analysis of variance followed by a post hoc least significant difference test (homogeneity of variance) or the Tukey test (heterogeneity of variance) with SPSS 20.0 software (SPSS, Inc., Chicago, IL, United States). The significance level was defined as $P<0.05$ or $P<0.01$.

\section{RESULTS}

\section{Analysis of Serum and Local Tissue Concentration}

The local concentration-time curve of vancomycin is shown in Figure 1A. The local vancomycin concentrations were significantly higher within 6 days after the implantation of VCS$\mathrm{H}$ and VCS-L, and reached peak levels at 234.21 and $135.37 \mathrm{mg} / \mathrm{L}$, respectively. At the 30th day, the concentrations of VCS-H and VCS-L were reduced to 123.37 and $65.32 \mathrm{mg} / \mathrm{L}$, respectively. As shown in Figure 1B, the serum concentration of icariin reached $48.39 \mu \mathrm{g} / \mathrm{L} 2 \mathrm{~h}$ after the first administration and maintained at a steady level of $50 \mu \mathrm{g} / \mathrm{L}$ in the following 30 days, which illustrated that icariin could be absorbed in the blood circulation and detected.

\section{Anti-infection and Bone Formation Assessments}

The levels of WBC and CRP in the model group were more than double the levels in the control group at the 4th week after the model was established (Figures 1C,D). VCS-H and VCS-L treatment significantly decreased the levels of WBC from $18.21 \times 10^{9} / \mathrm{L}$ to less than $10 \times 10^{9} / \mathrm{L}$, and decreased the levels of CRP from 9.54 to $4 \mathrm{mg} / \mathrm{L}$ at the 4 th week after treatment. There was no significant difference in CRP or WBC in the control group, VCS-H, VCS-L, and VCS-icariin groups after treatment, which illustrated that VCS had an excellent antiinflammatory effect. As shown in Figures 1E,F, ALP and OC in serum were decreased by $50 \%$ at the 4 th week after the model was established, and the levels were improved by VCS-icariin after treatment. However, serum ALP and OC in the VCS-H group were significantly lower than in the VCS-L group after treatment.
These results indicated that the high local concentration of vancomycin reduced the levels of bone formation indicators in the peripheral blood. On the other hand, serum ALP and OC could be increased via the intragastric administration of icariin.

\section{Icariin Promoted Bone Formation during the Post-infection Treatment Period}

At the 8th week after treatment, the rabbits in the model group had a large number of infected sinuses, and white and yellow pus overflowed from the wounds. The bone defects in the VCSicariin group were the smallest in the three treatment groups, and those in the VCS-H group were the largest (Figure 2A). The bone defect in the model group was evident in the Micro-CT results of three-dimensional reconstruction figures of the tibia and the ROI (Figures 2B,C). The defect areas in the VCS-L, VCS-H and VCSicariin groups were significantly reduced, moreover, the bone mass was more improved in the VCS-icariin group than in the VCS-L and VCS-H groups. As shown in Table 2, the indicators of $\mathrm{BV} / \mathrm{TV}$ and BMD in the model group were $10.34 \pm 1.62 \%$ and $0.32 \pm 0.03 \mathrm{~g} / \mathrm{cm}^{2}$ at the 8 th week after treatment. The VCSicariin treatment increased BV/TV and BMD to $75.33 \pm 4.25 \%$ and $1.26 \pm 0.04 \mathrm{~g} / \mathrm{cm}^{2}$, respectively, which were significantly higher than the indicators in the VCS-H group. These results indicated that bone healing after the anti-infection treatment was influenced by a high local concentration vancomycin; however, icariin noticeably promoted bone repair.

Areas in green, red, and yellow in the fluoroscope images (Figure 3) represented regions of calcium precipitation of tissue mineralization labeled by fluorochromes at 7, 14, and 21 days before euthanasia; the deposits of the dyes were seen around the bone defect in the sequence of their administration. As shown in Table 3, the MAR and BFR in VCS-icariin group were more than twofold higher than in the VCS-H group during the 21 days before euthanasia. The stimulating effect of icariin on new bone formation was indicated via the increased speed of new bone formation and the quality of new bone. Morphometric analysis indicated a pronounced decrease in N.Ob/T.Ar and N.Ob/B.pm induced by $S$. aureus, but this decrease was mitigated by VCSL, VCS-H, and VCS-icariin treatment. Moreover, N.Ob/T.Ar and N.Ob/B.pm in the VCS-icariin group were more than twofold higher than in the VCS-L and VCS-H groups. N.Ob/T.Ar and N.Ob/B.pm were significantly higher in the VCS-L group than in the VCS-H group (Figures 4A,B). Masson's Trichrome staining confirmed that the defect in the model group was filled with fibrous tissue. In the VCS-L, VCS-H and VCS-icariin groups, newly formed osteoid tissue and woven bone were easily identified, and the interface between the nascent bone and the host bone was still distinguishable (Figure 4C). The mature bone area rates were $10.25 \pm 2.36 \%$ in the model group, which were significantly lower than in the three treatment groups. The mature bone area rates in the VCS-icariin group was sixfold higher than the model group, and threefold higher than the VCS$\mathrm{H}$ group. The Masson's Trichrome staining results revealed more mature bone tissue in the VCS-icariin group and less mature bone tissue in the VCS-L and VCS-H groups (Figure 4D). Both $\mathrm{H} \& \mathrm{E}$ and Masson's Trichrome staining results revealed a decrease 

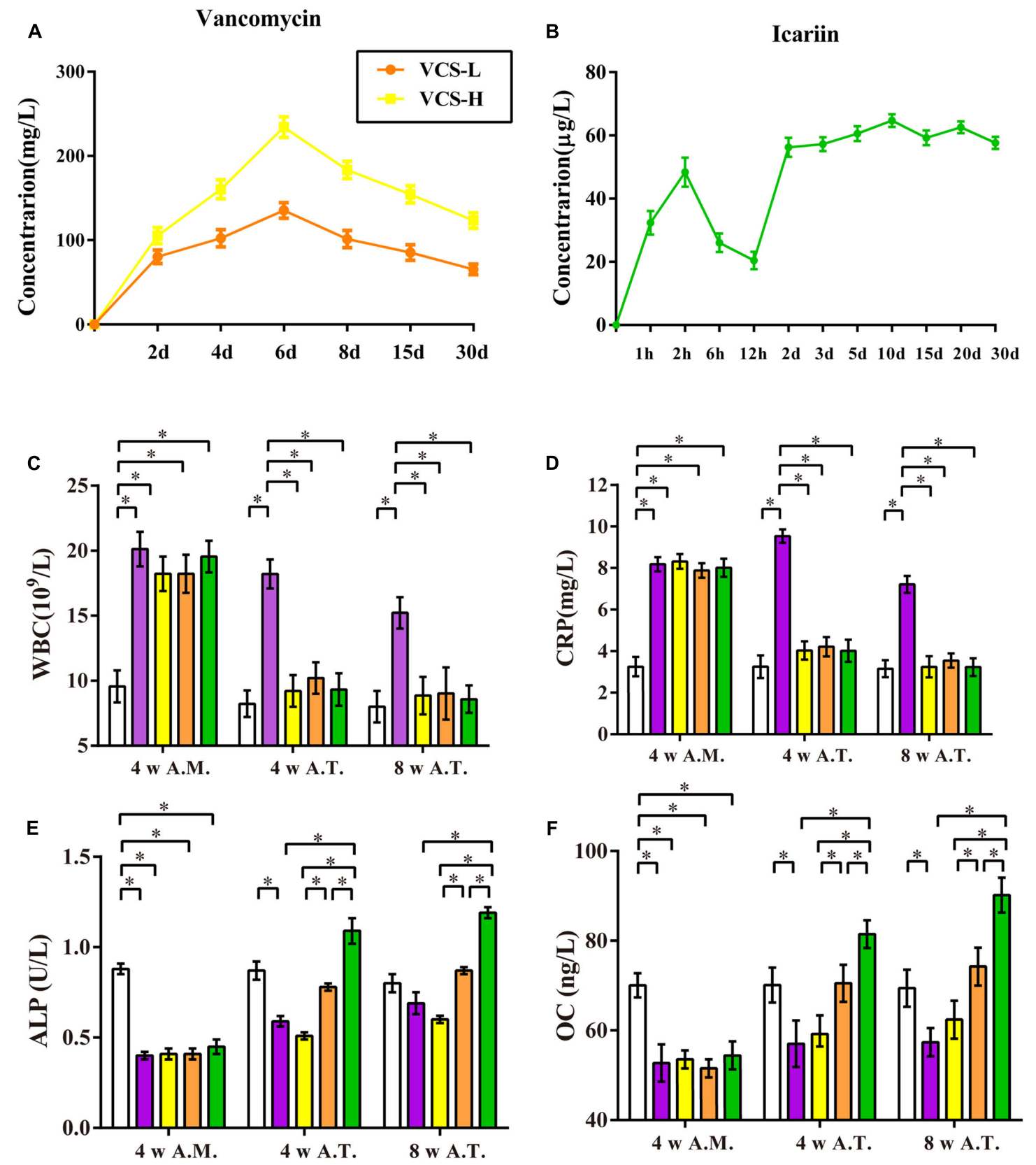

Control group $\square$ Model group $\square$ VCS-H group $\square$ VCS-L group

VCS-icariin group

FIGURE 1 | (A) Local concentration-time curves of vancomycin. (B) Serum concentration-time curve of icariin. (C-F) The results of CRP, WBC, ALP, and osteocalcin in the rabbit serum at the fourth week after infection and the fourth week and eighth week after treatment, ${ }^{*} P<0.05 .4$ W A.M., 4 weeks after the model was established; 4 w A.T., 4 weeks after treatment; 8 w A.T., 8 weeks after treatment.

in the number of osteoblasts and the amount of mature bone tissue in the VCS-L and VCS-H groups. In the VCS-icariin group, there were more osteoblasts and mature bone tissues around bone trabeculae compared with the VCS-H group.

The immunohistochemical analysis of OC in the tibia tissue indicated weaker positive staining for OC in the model group, which can be attributed to $S$. aureus infection $(P<0.05)$. There was no significant difference between the VCS-H group and the model group, indicating that bone repair was inhibited in the VCS-H group. The level of positive staining for OC in the tibia samples in the VCS-icariin group was $0.46 \pm 0.003 \%$, significantly higher than in the VCS-L group. In addition, there was a significant difference between the VCS-L group and the VCS-H group (Figure 4E). 

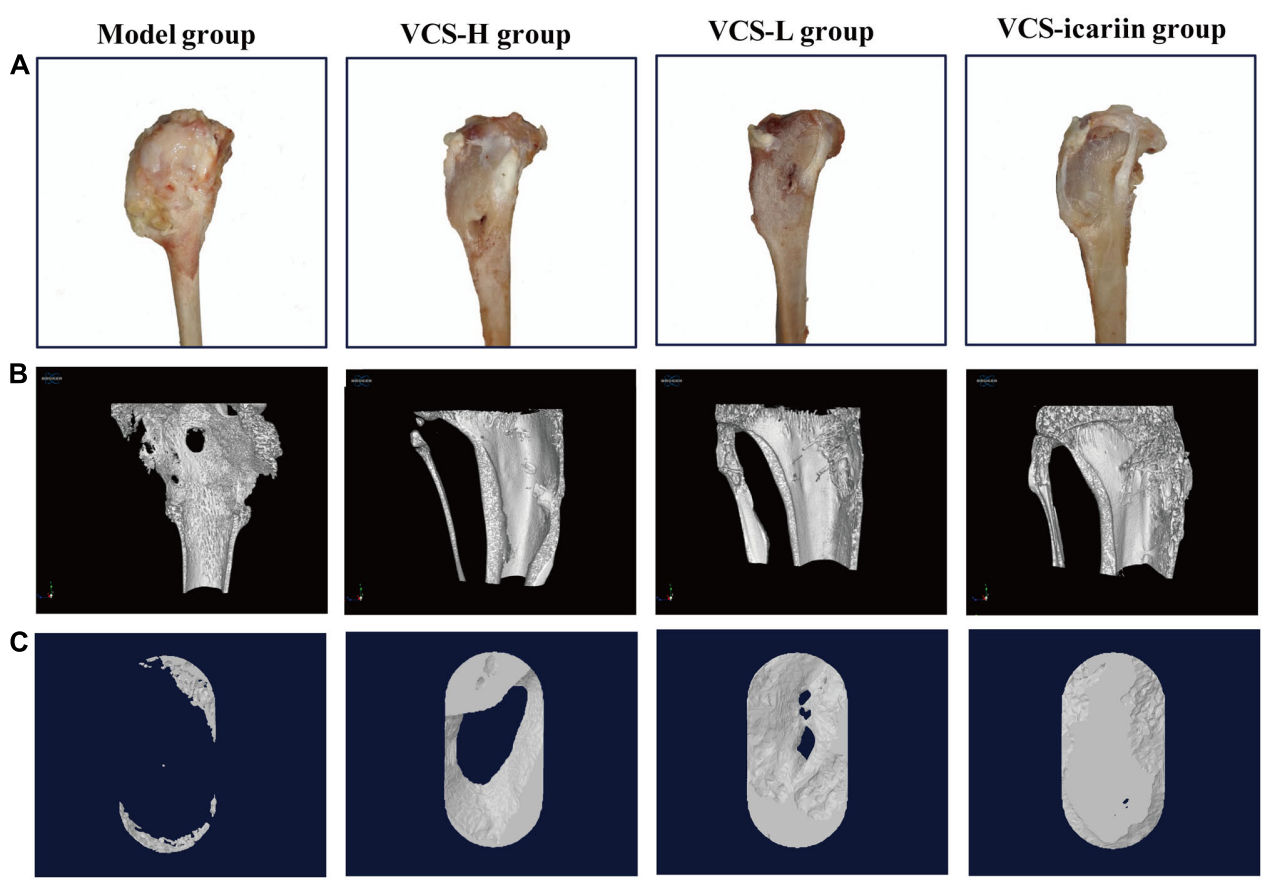

FIGURE 2 | (A) Appearance of the rabbit tibias 8 weeks after treatment with VCS-L, VCS-H, and VCS-icariin. (B) Three-dimensional reconstruction of bone defects of the tibia in bone infection model rabbits that underwent 8 weeks of treatment with VCS-L, VCS-H, and VCS-icariin. (C) Three-dimensional reconstruction of the bone defect of the ROI in the model, VCS-L, VCS-H, and VCS-icariin groups.

TABLE 2 | Effects of icariin on tibia microarchitecture in the rabbits $(n=3)$.

\begin{tabular}{|c|c|c|c|c|}
\hline \multirow[t]{2}{*}{ Group } & BV/TV (\%) & \multirow[t]{2}{*}{$\operatorname{BMD}\left(\mathrm{g} / \mathrm{cm}^{2}\right)$} & BV/TV (\%) & \multirow[t]{2}{*}{$\mathrm{BMD}\left(\mathrm{g} / \mathrm{cm}^{2}\right)$} \\
\hline & 4 weeks & & 8 weeks & \\
\hline Model & $2.60 \pm 0.04$ & $0.10 \pm 0.01$ & $10.34 \pm 1.62$ & $0.32 \pm 0.03$ \\
\hline VCS-H & $15.21 \pm 2.14^{* *}$ & $0.20 \pm 0.02 *$ & $30.14 \pm 2.32^{* *}$ & $0.58 \pm 0.04^{*}$ \\
\hline VCS-L & $23.90 \pm 1.43^{* *} ※$ & $0.45 \pm 0.01^{* *} ※$ & $58.52 \pm 3.58^{* * \#} ※$ & $0.96 \pm 0.02^{* *} ※$ \\
\hline VCS-icariin & $40.14 \pm 3.47^{* * \# \#) ※ \%}$ & $0.77 \pm 0.04^{* * \#} \ddot{*} \times$ & 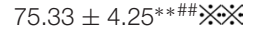 & 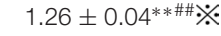 \\
\hline
\end{tabular}

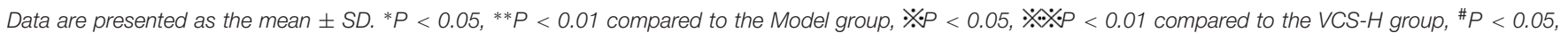
${ }^{\# \#} P<0.01$ compared to the VCS group. Bone volume/tissue volume (BV/TV); bone mineral density (BMD).

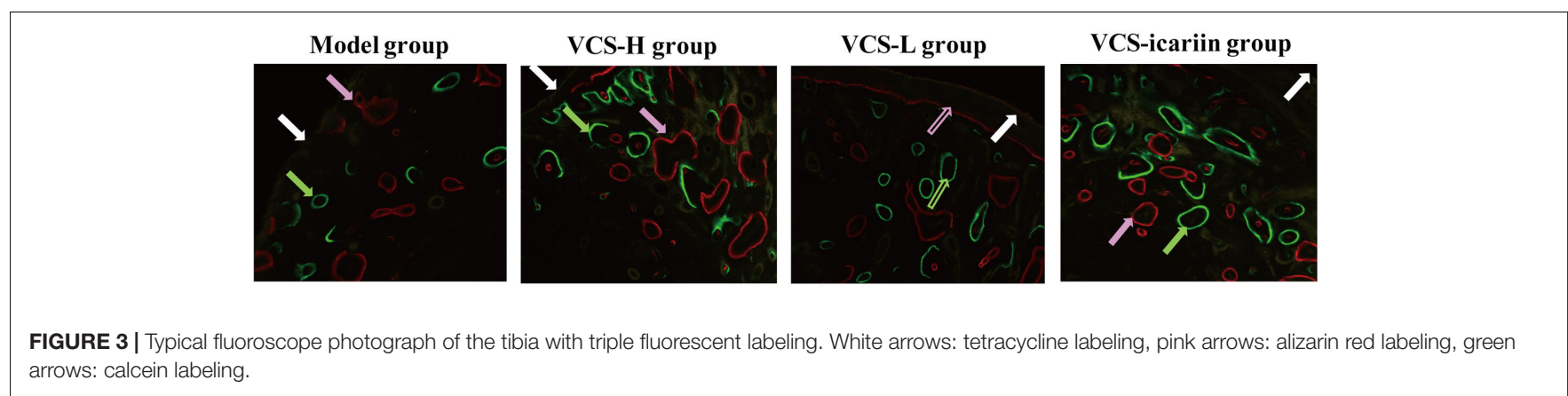

\section{Icariin Reversed the Inhibition of ROBs Caused by Vancomycin}

As shown in Figure $\mathbf{5 A}$, ROBs treated with vancomycin at $0.1,1$, and $5 \mathrm{mg} / \mathrm{mL}$ exhibited considerable changes in cell morphology and cell proliferation. The proliferation capability of ROBs treated with $0.1 \mathrm{mg} / \mathrm{mL}$ vancomycin was reduced to approximate $80 \%$ compared to the control ROBs. Icariin significantly increased the proliferation capability of ROBs induced with $0.1 \mathrm{mg} / \mathrm{mL}$ vancomycin (Figure 5B). As evident from the results (Figures 5C,D), $0.1 \mathrm{mg} / \mathrm{mL}$ vancomycin 
TABLE 3 | The dynamic parameters of the tibia with triple fluorescent labeling $(n=3)$.

\begin{tabular}{|c|c|c|c|c|}
\hline \multirow[t]{2}{*}{ Group } & MAR $(\mu \mathrm{m} / \mathrm{d})$ & $\operatorname{BFR}\left(\mu \mathrm{m}^{2} / \mu \mathrm{m} / \mathrm{d}\right)$ & MAR $(\mu \mathrm{m} / \mathrm{d})$ & $\operatorname{BFR}\left(\mu \mathrm{m}^{2} / \mu \mathrm{m} / \mathrm{d}\right)$ \\
\hline & \multicolumn{2}{|c|}{ Tetracycline and alizarin red labeling } & \multicolumn{2}{|c|}{ Alizarin red and calcein labeling } \\
\hline VCS-H & $1.98 \pm 0.13^{*}$ & $1.65 \pm 0.29 *$ & $2.35 \pm 0.24^{*}$ & $1.56 \pm 0.20^{*}$ \\
\hline VCS-L & $2.85 \pm 0.16^{* *} ※$ & $2.55 \pm 0.16^{* *} ※$ & $3.44 \pm 0.22 * * ※$ & $2.36 \pm 0.18^{* *} ※$ \\
\hline VCS-icariin & 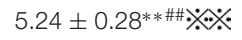 & $2.98 \pm 0.29 * * \# ※$ & $5.89 \pm 0.15^{* * \#} ※$ & $3.55 \pm 0.10^{* * \#} ※$ \\
\hline
\end{tabular}

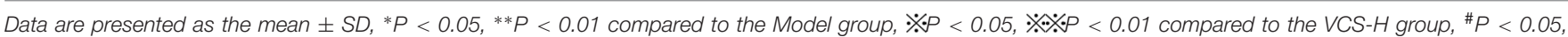
$\# P<0.01$ compared to the VCS-L group. Mineral appositional rate (MAR); bone formation rate (BFR).

increased the percentage of ROBs in the G1 phase of the cell cycle and decreased the percentage of cells in G2 and S phases. However, treatment with $0.01,0.02$, and $0.05 \mathrm{mg} / \mathrm{mL}$ icariin led to increase cell cycle arrest in the G2, S phases, meanwhile, G1 phase was reduced significantly, as compared to the ROBs treated with $0.1 \mathrm{mg} / \mathrm{mL}$ vancomycin.

Alkaline phosphatase activities in ROBs induced with vancomycin were significantly reduced compared to the control ROBs (Figure 5E). Nevertheless, icariin dramatically increased ALP activity at doses of $0.01,0.02$, and $0.05 \mathrm{mg} / \mathrm{mL}$ (Figure 5F). ALP positive staining also showed that icariin increased ALP activity in osteoblasts, compared to the group without icariin (Figure 5G).

Taken together, vancomycin could reduce cell proliferation and differentiation; when its concentration exceeded $0.1 \mathrm{mg} / \mathrm{mL}$, icariin could reverse the inhibition of ROBs.

\section{Reversal Mechanism of Icariin on Osteoblasts Inhibited by Vancomycin}

RT-PCR data in Figure 6A showed that vancomycin at doses of $0.1 \mathrm{mg} / \mathrm{mL}$ significantly reduced mRNA expression of BMP2 and Runx2 in ROBs, which demonstrated the inhibitory effect of vancomycin on ROBs. The ROBs co-cultured with vancomycin and icariin significantly enhanced the mRNA expression of BMP2 and Runx2 in ROBs, compared with ROBs co-cultured with vancomycin. As shown in Figures 6B,C, the western blot of BMP2 and Runx2 proteins revealed the same results as gene expression. Western blot data showed that the treatment of ROBs with vancomycin at $0.1 \mathrm{mg} / \mathrm{mL}$ and icariin at $0.05 \mathrm{mg} / \mathrm{mL}$ significantly enhanced the protein expression of BMP2 and Runx2, compared with ROBs that were treated with vancomycin.

RT-PCR results showed that ROBs treated with vancomycin had a lower ratio of OPG/RANKL, and icariin at doses of 0.01 , 0.02 , and $0.05 \mathrm{mg} / \mathrm{mL}$ showed an appreciable effect on the OPG/RANKL ratio. The western blot results showed that the ROBs treated with icariin had a higher level of OPG protein expression and a lower level of RANKL protein expression than the ROBs treated with vancomycin, which produced a higher OPG/RANKL ratio in the ROBs treated with icariin. In summary, the results described above demonstrated that icariin treatment can reverse the inhibitory effect of a high dose of vancomycin on ROBs by regulating the dynamic balance of bone resorption and bone formation via the activation of BMP signaling and the inhibition of the combination of RANKL and RANK.

\section{DISCUSSION}

Vancomycin is the most effective antibiotic for the treatment of bone infection with $S$. aureus. However, many reports indicated that high concentration of vancomycin inhibited bone healing and decreased the number of osteoblasts. Approximately 10$15 \%$ of patients with bone infection experienced a long bone union process, delayed union or non-union after anti-infection treatment via the local placement of VCS. In our previous studies, the local concentration of vancomycin in patients with single $100 \mathrm{mg}$ dose could reach a very high level, probably exceed the inhibitory concentration of vancomycin on osteoblasts. In the clinic, a higher dose of VCS was always implanted into the local site, which induced a long bone union process, delayed union or non-union after anti-infection treatment in patients. The current knowledge of Chinese medical plants suggests that they are a viable source of potential osteoprotective agents. For example, Herba Epimedii exerted osteoplastic effects on bone union and was identified as a potential treatment for delayed union and nonunion of the bone. In previous studies, the main component in Herba Epimedii, flavonoids such as icariin, epimedins A, B, and C were shown to be the major contributor to osteoplastic effects on osteoporosis, osteoarthritis and other bone disease (Zhou et al., 2013). Icariin was shown to be the most effective component, which produced the most significant promoting effect on the proliferation in osteoblasts, and activated estrogen receptor alpha (ER) and stimulate ER-dependent osteoblastic functions (Meng et al., 2005; Jin et al., 2013; Xiao et al., 2014). We preliminarily tested the osteoplastic effect of icariin at different doses (5.43, 10.86 , and $21.72 \mathrm{mg} / \mathrm{kg} / \mathrm{day}$ ), found that $10.86 \mathrm{mg} / \mathrm{kg} / \mathrm{day}$ was the effective dose. In this study, the mean serum concentrationtime curves showed that icariin was absorbed into the blood and maintained at an effective concentration of $50 \mu \mathrm{g} / \mathrm{L}$. Based on the above findings, we hypothesized that high doses of vancomycin inhibited bone healing at the local site, and icariin exerted potential osteoplastic effects on osteoblasts, which could provide a new therapeutic method for delayed union or non-union after anti-infection treatment via the local placement of VCS in bone infection patients.

To examine the hypothesis in this study, The rabbits induced with S. aureus were treated with VCS-L, VCS-H and VCS-icariin. 


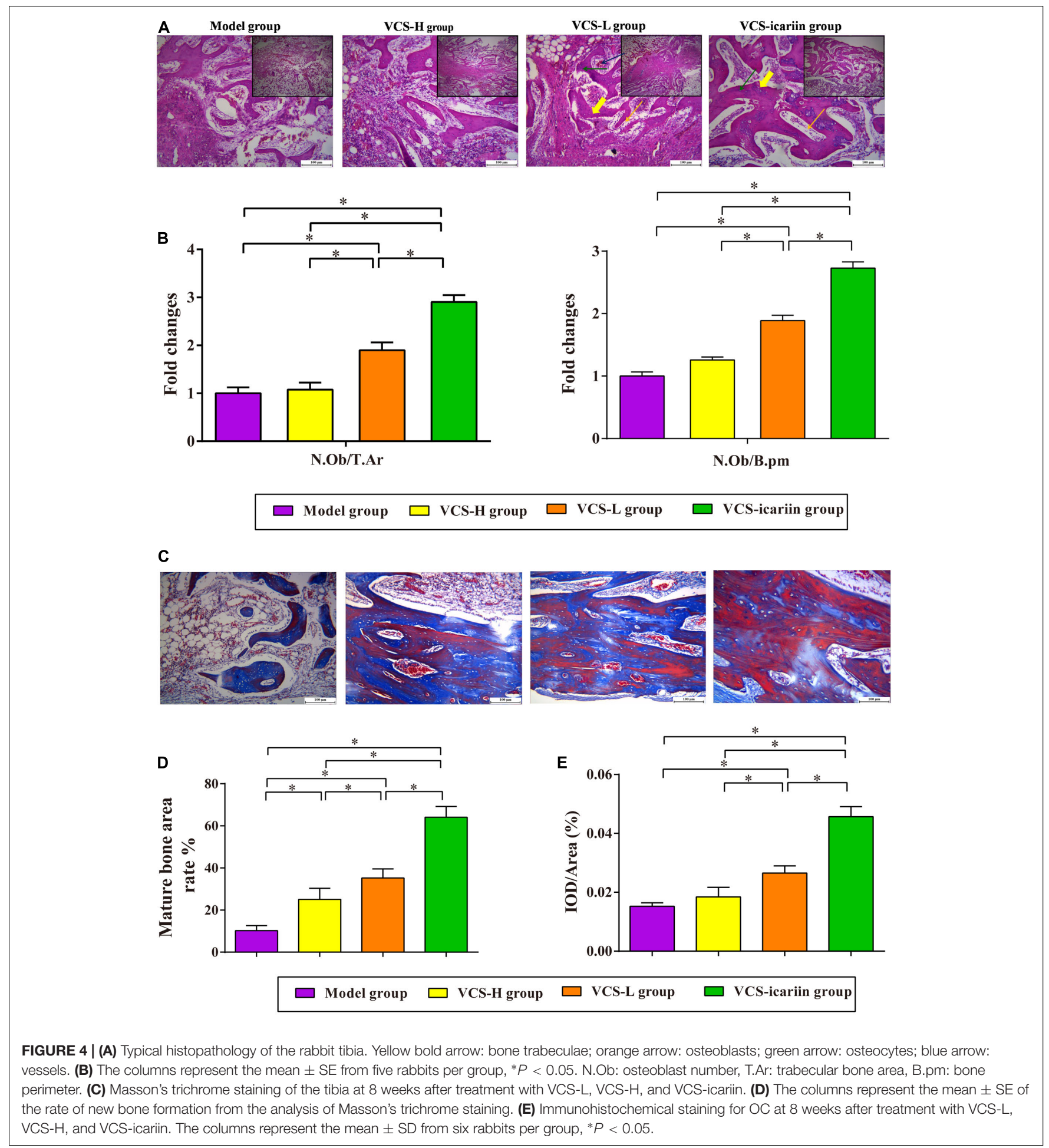

The Micro-CT data demonstrated that the shortest symphysis time was in the VCS-icariin group among the three treatment groups, and a shorter symphysis time was detected in the VCSL group compared to the VCS-H group. Morphometric analysis results indicated that the number of active osteoblasts lining the bone trabeculae and the areas of mature bone tissues were improved after icariin treatment, although there were fewer osteoblasts and less mature bone tissue in the VCS-H group than in the VCS-L group. The triple fluorescence labeling test showed that the speed of bone formation in VCS-icariin group was higher than in the VCS group and was lower in the VCS-H group than in the VCS-L group. All of these results suggested the inhibition 
A

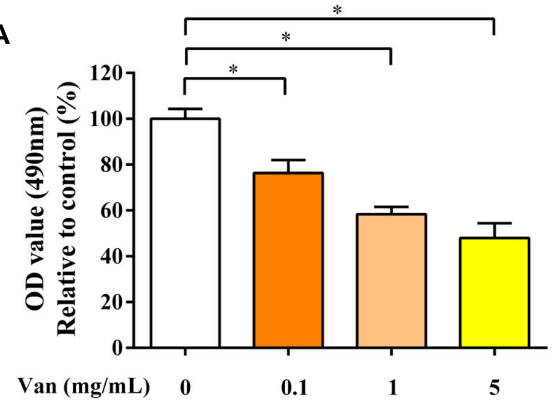

B

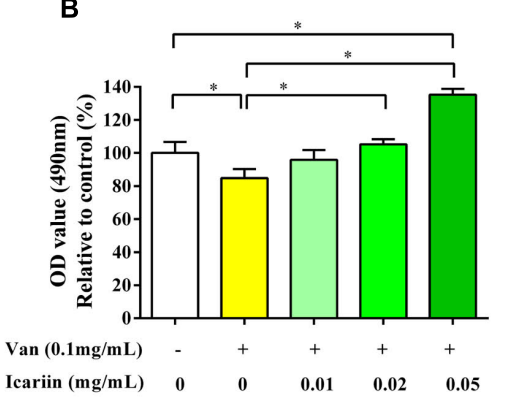

C
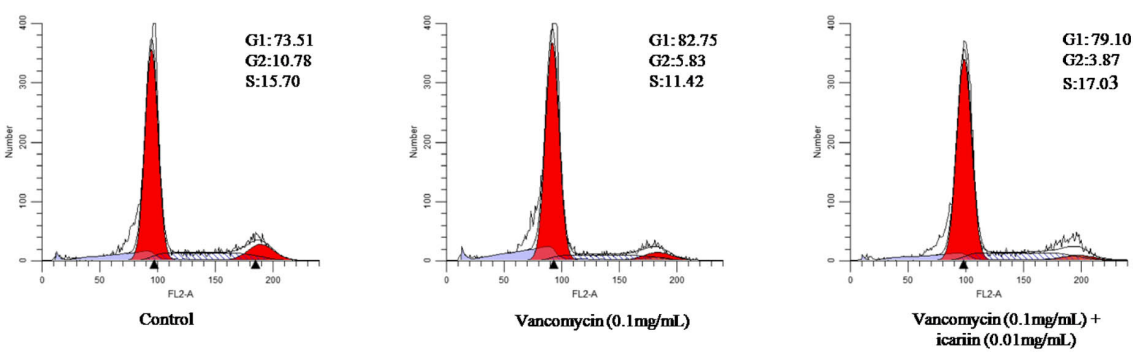

D
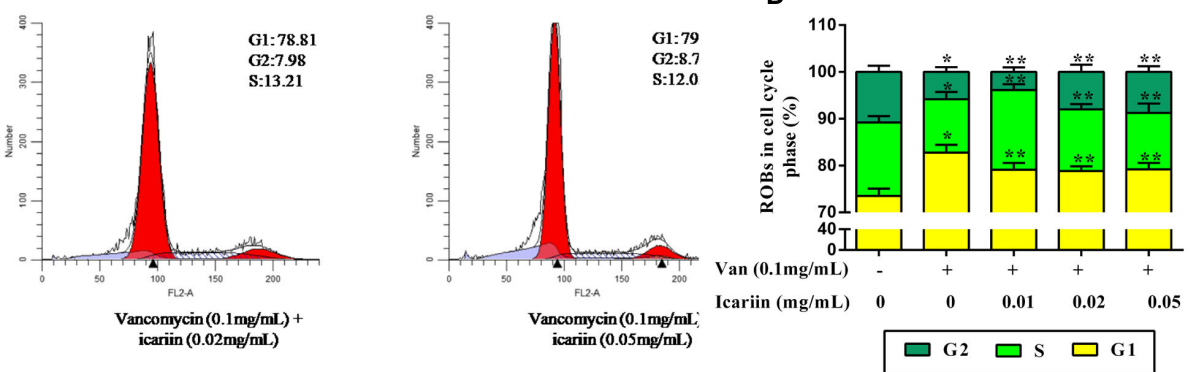

E

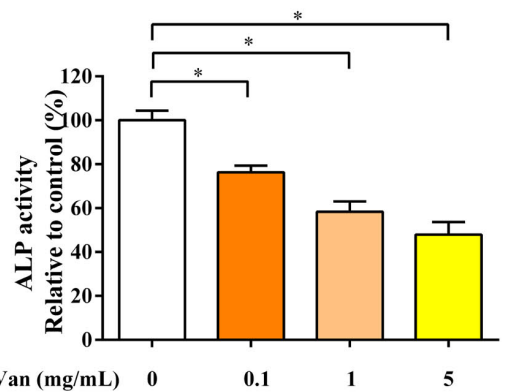

$\mathbf{F}$

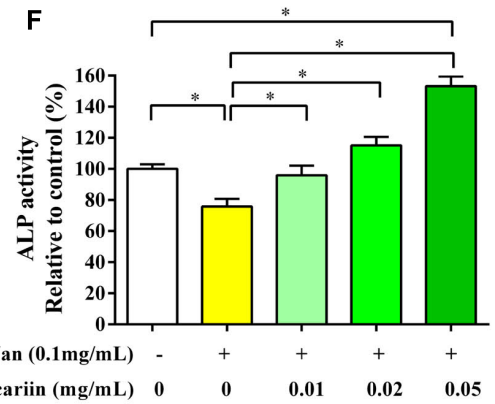

$\begin{array}{llllll}\text { Icariin }(\mathrm{mg} / \mathrm{mL}) & 0 & 0 & 0.01 & 0.02 & 0.05\end{array}$

G

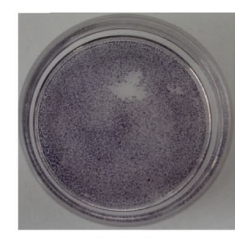

Control

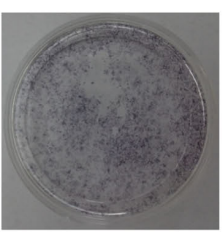

Van $(0.1 \mathrm{mg} / \mathrm{mL})$

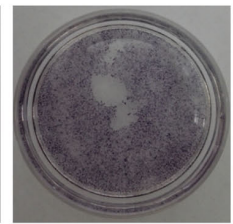
Van $(0.1 \mathrm{mg} / \mathrm{mL})^{+}$
Icariin $(0.01 \mathrm{mg} / \mathrm{mL})$

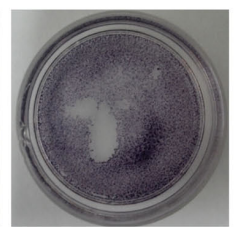

Van $(0.1 \mathrm{mg} / \mathrm{mL})^{+}$ Icariin $(0.02 \mathrm{mg} / \mathrm{mL})$

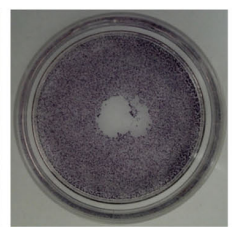

Van $(0.1 \mathrm{mg} / \mathrm{mL})+$ Icariin $(0.05 \mathrm{mg} / \mathrm{mL})$

FIGURE 5 | (A) The proliferation capability of ROBs treated with vancomycin, ${ }^{*} P<0.05$. (B) ROBs treated with vancomycin and icariin, ${ }^{*} P<0.05$. (C) Cell cycle analysis was performed by flow cytometry using propidium iodide DNA staining of ROBs. (D) The percentages of ROBs in the cell cycle phases were shown in the percentage histogram. Each value represented mean $\pm \mathrm{SD}$ of three independent experiments. ${ }^{*} P<0.05$, compared to the control ROBs, ${ }^{*} P<0.05$ compared to ROBs treated with vancomycin. (E) ALP level of ROBs treated with vancomycin, ${ }^{*} P<0.05$. (F) ALP level of ROBs treated with vancomycin and icariin, ${ }^{*} P<0.05$.

(G) ALP positive staining of ROBs treated with vancomycin and icariin. 
A

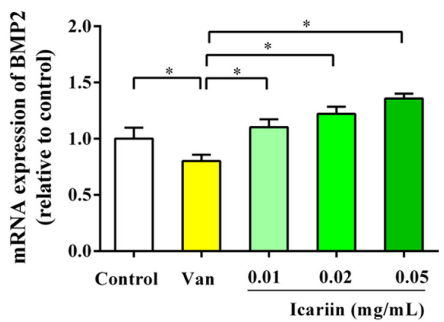

B

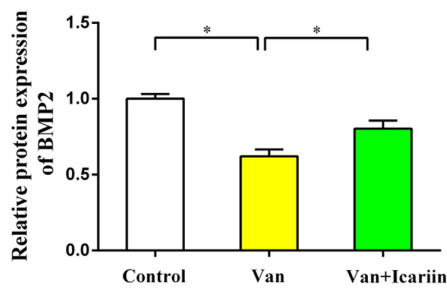

C

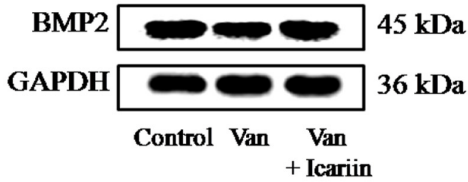

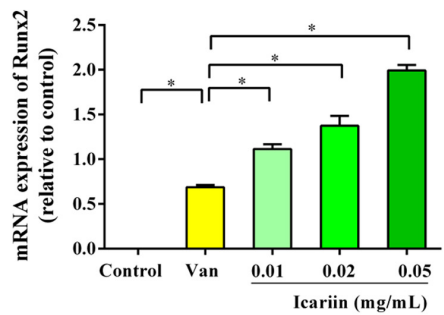
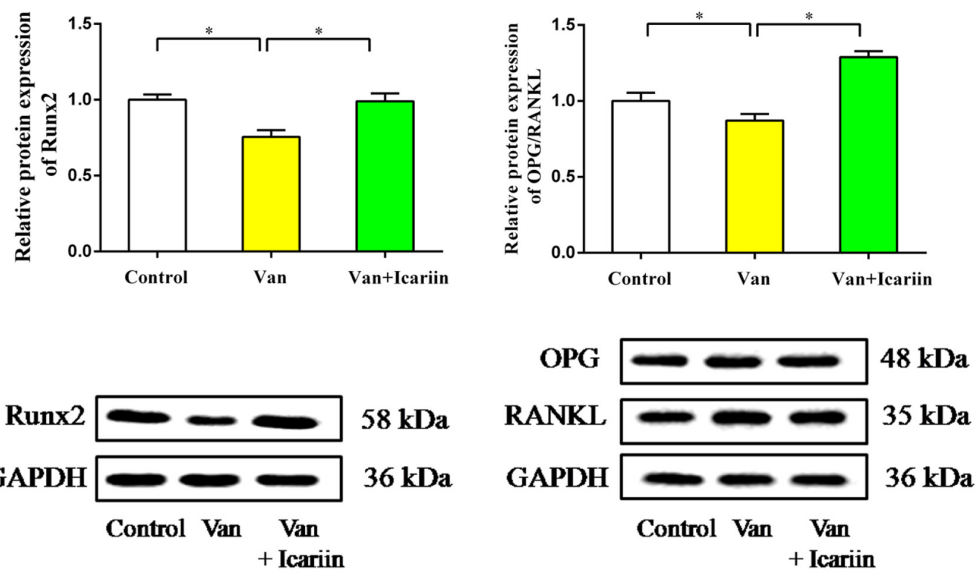

FIGURE 6 | (A) RT-PCR results, ${ }^{*} P<0.05$. (B) Western blot analysis, ${ }^{*} P<0.05$. (C) Protein expression in ROBs after co-culture with vancomycin and icariin.

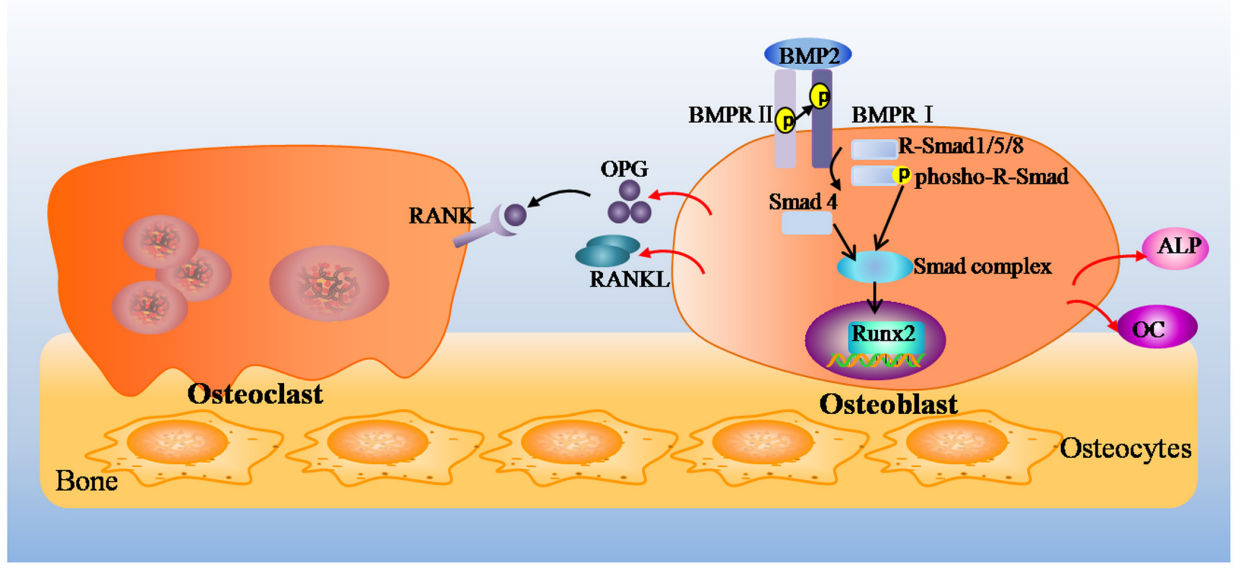

FIGURE 7 | The mechanism of OPG/RANKL pathway and BMP2/Runx2 pathway on bone repair.

of bone healing by a high concentration of vancomycin, and the activation of bone remodeling with icariin. Icariin elevates new bone formation capability and accelerates the speed of bone mineralization around the bone defect locally. Since OC was secreted by osteoblasts and accumulated in the extracellular matrix of bone, it was considered one of the sensitive markers associated with bone formation. In this study, at the end of treatment with VCS-L and VCS-H, and VCS-icariin, the VCS-H group exhibited less positive staining for OC, and the VCS-icariin group exhibited more positive staining for OC than other groups.
In vitro, the results showed that the proliferation of ROBs was inhibited by blocking the cell in the G1 phase, when cells were co-cultured with different concentrations of vancomycin, and a positive correlation between this effect and vancomycin concentration was apparent. However, icariin treatment led to increase cell cycle arrest in G2/S phase with prolonged incubation time. We concluded that icariin can affect the proliferation of osteoblasts by promoting DNA synthesis. During early stages of osteoblast differentiation, osteoblasts synthesize ALP and other osteoblastic differentiation markers, ultimately leading to 
the induction of extracellular matrix calcification (Babey et al., 2015). In this study, the ALP activity was inhibited by treated with $0.1 \mathrm{mg} / \mathrm{mL}$ vancomycin, and effectively elevated by icariin during osteoblast differentiation. Moreover, a positive correlation between this effect and the icariin concentration was observed. However, in previous studies, cell numbers were reduced by $50 \%$ compared with the control group at $24 \mathrm{~h}$ after they were cocultured with $0.4 \mathrm{mg} / \mathrm{mL}$ vancomycin and human dural fibroblast (Goldschmidt et al., 2016). The differences might be due to the variety of species and genera of the cells, and the different characteristics of cellular metabolic activity. High concentrations of vancomycin inhibited mitochondrial energy via the regulation of lactate in the glycolysis process, and different cell lines showed various metabolic characteristics (Duewelhenke et al., 2007; Philp et al., 2017). Although the inhibitory concentrations of vancomycin were diverse in previous studies, the dose dependent tendency of inhibition on the proliferation of osteoblasts was obvious. In addition, cell proliferation and differentiation were investigated at $24 \mathrm{~h}$ after co-culture with vancomycin and ROBs in this study, and the quantity and metabolic function of ROBs in the following period of time deserve further research.

Bone remodeling is a cellular process mediated by osteoclasts and osteoblasts, and this process normally occurs in a tightly regulated sequence of events, where the amount of formed bone equals the amount of resorbed bone, thereby completely restoring the removed bone (Chen et al., 2015). Osteoclasts differentiate from monocyte/macrophage lineage precursors under regulation of two cytokines, macrophage-colony-stimulating factor and RANKL (Xu et al., 2016). RANKL binds to its receptor RANK, which promotes the differentiation, multinucleation, activation, and survival of osteoclasts. OPG, a soluble decoy receptor for RANKL, inhibits osteoclastogenesis by blocking the RANKLRANK interaction, which inhibits osteoclast formation and differentiation and induces apoptosis (Delnaz et al., 2010; Liò et al., 2012). Furthermore, OPG and RANKL are fundamental proteins secreted by mature osteoblasts (Szentpétery et al., 2017). Base on the above, any modification in the OPG-to-RANKL ratio can induce either excessive bone resorption or, in contrast, excessive bone formation. In short, Osteoblasts and osteoblastic lineage cells modulate the formation and activity of osteoclasts by expressing RANKL and OPG, which induce and inhibit osteoclastogenesis, respectively (Krum et al., 2010). On the other hand, BMPs, belong to the transforming growth factor $\beta$ (TGF$\beta$ ) superfamily, which have been identified as inducers of ectopic bone and cartilage formation (Yang et al., 2014). BMP2 is one of the most important cytokines playing important roles in bone development and fracture repair (Jang et al., 2012). As shown in Figure 7, BMP2 binds to the cell surface type I receptor (BMPR I), type II receptor (BMPR II) to form a complex, then the complex phosphorylatate receptor-activated Smad (RSmad 1/5/8). The activated Smads combine with Smad 4 (CoSmad), which come into the nucleus, start-up Runx2 and Osterix expression, up-regulate a variety of special osteoblast mRNAs and protein expression, such as ALP, collagen I, OC, osteopontin, finally promote the synthesis of bone matrix and bone formation (Matsubara et al., 2008; Chen et al., 2012). In brief, BMP2 deems to control the expression and functions of Runx2 through Smad signaling and be essential for osteoblast differentiation (Derek et al., 2015).

The results of the mRNA and protein expression showed that the gene expression of BMP2 and Runx2 and the ratio of OPG/RANKL were decreased in the ROBs by different concentrations of vancomycin and were increased in ROBs by icariin treatment. Based on the results presented above, it was hypothesized that vancomycin inhibited the proliferation and differentiation of ROBs by inhibiting the BMP2/Runx2 pathway and OPG/RANKL pathways, which were the dominant factors that regulated bone formation and bone resorption. Meanwhile, icariin stimulated this balance by up-regulating BMP2 and Runx2 expression. Icariin up-regulated OPG and down-regulated RANKL mRNA and protein expression, leading to an increased OPG/RANKL ratio. Whether the balance between bone formation and bone resorption fully mediated the effects of icariin in vivo merits to be further investigated.

\section{CONCLUSION}

We demonstrated that the local implantation of VCS can control infection in model rabbits; however, a high local concentration of vancomycin significantly reduced bone formation. Icariin exhibited osteoplastic properties on osteoblasts that had been inhibited with high doses of vancomycin in vitro, thus indicating that icariin may be worthy of further investigation as a potential agent for the treatment of delayed union and non-union of the bone after anti-infection treatment with vancomycin in bone infection patients.

\section{AUTHOR CONTRIBUTIONS}

YZ and LS wrote the manuscript. YZ, ZM, NW, XW, and XH performed the experiments, YH, DS, and CW conceived or designed the studies. All authors contributed to analyzing the data.

\section{FUNDING}

This work was supported by The Zhejiang Provincial Natural Science Foundation, China (LY17H290002), Science and Technology Project of Zhejiang Province (2016F10027), The Zhejiang Provincial Traditional Chinese Medicine Science and Technology Fund (2017ZA016, 2016ZB003), The Zhejiang Provincial Medical and Health Science and Technology Fund (2017KY271), The Science and Technology Innovation Team Project of Ningbo Science and Technology Bureau, China (no. 2015C110027), and Key Laboratory of Ningbo, China (no. 2016A22002).

\section{ACKNOWLEDGMENT}

The authors are thankful to Wang Ping'er (Institute of Orthopaedics and Traumatology of Zhejiang Province) for the Micro-CT analysis in this research work. 


\section{REFERENCES}

Babey, M., Wang, Y., Kubota, T., Fong, C., Menendez, A., ElAlieh, H. Z., et al. (2015). Gender-specific differences in the skeletal response to continuous PTH in mice lacking the IGF1 receptor in mature osteoblasts. J. Bone Miner. Res. 30, 1064-1076. doi: 10.1002/jbmr.2433

Bian, Q., Liu, S. F., Huang, J. H., Yang, Z., Tang, D. Z., Zhou, Q., et al. (2012). Oleanolic acid exerts an osteoprotective effect in ovariectomy-induced osteoporotic rats and stimulates the osteoblastic differentiation of bone mesenchymal stem cells in vivo. Menopause 19, 225-233. doi: 10.1097/gme. 0b013e3182272ef1

Che, C. T., Wong, M. S., and Lam, C. W. (2016). Nature products from chinese medicines with potential benefits to bone health. Molecules 21:239. doi: 10.3390/ molecules21030239

Chen, G. Q., Deng, C. X., and Li, Y. P. (2012). TGF- $\beta$ and BMP signaling in osteoblast differentiation and bone formation. Int. J. Biol. Sci. 8, 272-288. doi: 10.7150/ijbs.2929

Chen, H., Senda, T., and Kubo, K. Y. (2015). The osteocyte plays multiple roles in bone remodeling and mineral homeostasis. Med. Mol. Morphol. 48, 61-68. doi: 10.1007/s00795-015-0099-y

Delnaz, R., Holliday, K. L., Pye, S. R., Boonen, S., Borghs, H., Vanderschueren, D., et al. (2010). Genetic variation in the RANKL/RANK/OPG signaling pathway is associated with bone turnover and bone mineral density in men. J. Bone Miner. Res. 25, 1830-1838. doi: 10.1002/jbmr.78

Derek, P. B., Rachel, H. C., Satnam, S., Catherine, G., and Finian, M. (2015). BMP signalling: agony and antagony in the family. Trends Cell Biol. 25, 249-264. doi: $10.1016 /$ j.tcb.2014.12.004

Dong, Y. L., Liu, W. Q., Lei, Y. L., Wu, T. X., Zhang, S. W., Guo, Y. C., et al. (2017). Effect of gelatin sponge with colloid silver on bone healing in infected cranial defects. Mater. Sci. Eng. C Mater. Biol. Appl. 70, 371-377. doi: 10.1016/j.msec. 2016.09.015

Duewelhenke, N., Krut, O., and Eysel, P. (2007). Influence on mitochondria and cytotoxicity of different antibiotics in high concentrations on primary human osteoblasts and cell lines. Antimicrob. Agents Chemother. 51, 54-63.

Eder, C., Schenk, S., Trifinopoulos, J., Külekci, B., Kienzl, M., Schildböck, S., et al. (2016). Does intrawound application of vancomycin influence bone healing in spinal surgery? Eur. Spine J. 25, 1021-1028. doi: 10.1007/s00586-015-3943-9

Farokhi, M., Mottaghitalab, F., Shokrgozar, M. A., Ou, K. L., Mao, C., and Hosseinkhani, H. (2016). Importance of dual delivery systems for bone tissue engineering. J. Control. Release 225, 152-169. doi: 10.1016/j.jconrel.2016.01.033

Goldschmidt, E., Rasmussen, J., Chabot, J. D., Gandhoke, G., Luzzi, E., Merlotti, L., et al. (2016). The effect of vancomycin powder on human dural fibroblast culture and its implications for dural repair during spine surgery. J. Neurosurg. Spine 25, 665-670.

Hassani Besheli, N., Mottaghitalab, F., Eslami, M., Gholami, M., Kundu, S. C., Kaplan, D. L., et al. (2017). Sustainable release of vancomycin from silk fibroin nanoparticles for treating severe bone infection in rat tibia osteomyelitis model. ACS Appl. Mater. 9, 5128-5138. doi: 10.1021/acsami.6b14912

Hsu, Y. H., Hu, C. C., Hsieh, P. H., Shih, H. N., Ueng, S. W., and Chang, Y. (2017). Vancomycin and ceftazidime in bone cement as a potentially effective treatment for knee periprosthetic joint infection. J. Bone Joint Surg. Am. 99, 223-231. doi: 10.2106/JBJS.16.00290

Jang, W. G., Kim, E. J., Kim, D. K., Ryoo, H. M., Lee, K. B., Kim, S. H., et al. (2012). BMP2 protein regulates osteocalcin expression via Runx2-mediated Atf6 gene transcription. J. Biol. Chem. 287, 905-915. doi: 10.1074/jbc.M111.253187

Jiao, L., Cao, D. P., Qin, L. P., Han, T., Zhang, Q. Y., Zhu, Z., et al. (2009). Antiosteoporotic activity of phenolic compounds from Curculigo orchioides. Phytomedicine 16, 874-881.

Jin, J., Li, Y., Kipletting Tanui, E., Han, L., Jia, Y., Zhang, L., et al. (2013). Fishing and knockout of bioactive compounds using a combination of highspeed counter-current chromatography (HSCCC) and preparative HPLC for evaluating the holistic efficacy and interaction of the components of Herba Epimedii. J. Ethnopharmacol. 147, 357-365. doi: 10.1016/j.jep.2013. 03.018

Krum, S. A., Chang, J., Miranda-Carboni, G., and Wang, C. Y. (2010). Novel functions for $\mathrm{NF}_{\mathrm{k}} \mathrm{B}$ : inhibition of bone formation. Nat. Rev. Rheumatol. 6, $607-611$.
Li, G. W., Xu, Z., Chang, S. X., Nian, H., Wang, X. Y., and Qin, L. D. (2014). Icariin prevents ovariectomy-induced bone loss and lower marrow adipogenesis. Menopause 21, 1007-1016. doi: 10.1097/GME.0000000000000201

Li, M., Zhang, N. D., Wang, Y., Han, T., Jiang, Y. P., Rahman, K., et al. (2016). Coordinate regulatory osteogenesis effects of icariin, timosaponin B II and ferulic acid from traditional Chinese medicine formulas on UMR106 osteoblastic cells and osteoblasts in neonatal rat calvaria cultures. J. Ethnopharmacol. 185, 120-131.

Liò, P., Paoletti, N., Moni, M. A., Kathryn, A., Emanuela, M., and Marco, V. (2012). Modelling osteomyelitis. BMC Bioinformatics 13:S12. doi: 10.1186/1471-210513-S14-S12

Matsubara, T., Kida, K., Yamaguchi, A., Hata, K., Ichida, F., Meguro, H., et al. (2008). BMP2 regulates osterix through Msx2 and Runx2 during osteoblast differentiation. J. Biol. Chem. 283, 29119-29125. doi: 10.1074/jbc.M80177 4200

Mendoza, M. C., Sonn, K. A., Kannan, A. S., Bellary, S. S., Mitchell, S. M., Singh, G., et al. (2016). The effect of vancomycin powder on bone healing in a rat spinal rhBMP-2 model. J. Neurosurg. Spin 25, 147-153. doi: 10.3171/2015.11. SPINE15536

Meng, F. H., Lia, Y. B., Xiong, Z. L., Jiang, Z. M., and Li, F. M. (2005). Osteoblastic proliferative activity of Epimedium brevicornum maxim. Phytomedicine 12, 189-193.

Mok, S. K., Chen, W. F., Lai, W. P., Leung, P. C., Wang, X. L., Yao, X. S., et al. (2010). Icariin protects against bone loss induced by oestrogen deficiency and activates oestrogen receptor-dependent osteoblastic functions in UMR 106 cells. Br. J. Pharmacol. 159, 939-949. doi: 10.1111/j.1476-5381.2009. 00593.x

Philp, A. M., Raja, S., Philp, A., Newton Ede, M. P., and Jones, S. W. (2017). The effect of vancomycin and gentamicin antibiotics on human osteoblast proliferation, metabolic function, and bone mineralization. Spine 42, 202-207. doi: 10.1097/BRS.0000000000001712

Rathbone, C. R., Cross, J. D., Brown, K. V., Murray, C. K., and Wenke, J. C. (2011). Effect of various concentrations of antibiotics on osteogenic cell viability and activity. J. Orthop. Res. 29, 1070-1074. doi: 10.1002/jor. 21343

Ren, Z. W., Wang, Y., Ma, S. Q., Duan, S., Yang, X. P., and Gao, P. (2015). Effective bone regeneration using thermosensitive poly $(N$-Isopropylacrylamide) grafted gelatin as injectable carrier for bone mesenchymal stem cells. ACS Appl. Mater. Interfaces 7, 19006-19015.

Shou, D., Dong, Y., Shen, L., Wu, R., Zhang, Y., Zhang, C., et al. (2014). Rapid quantification of tobramycin and vancomycin by UPLC-TQD and application to osteomyelitis patient samples. J. Chromatogr. Sci. 52, 501-507. doi: 10.1093/ chromsci/bmt069

Shou, D., Zhang, Y., Shen, L., Zheng, R., Huang, X., Mao, Z., et al. (2017). Flavonoids of Herba Epimedii enhances bone repair in a rabbit model of chronic osteomyelitis during post-infection treatment and simulates osteoblast proliferation in vitro. Phytother. Res. 31, 330-339.

Suwanprateeb, J., Kiertkrittikhoon, S., Kintarak, J., Suvannapruk, W., Thammarakcharoen, F., and Rukskul, P. (2014). In vivo assessment of new resorbable PEG-PPG-PEG copolymer/starch bone wax in bone healing and tissue reaction of bone defect in rabbit model. J. Mater. Sci. Mater. Med. 25, 2031-2039. doi: 10.1007/s10856-014-5249-6

Szentpétery, Á., Horváth, Á., Gulyás, K., Pethö, Z., Bhattoa, H. P., Szántó, S., et al. (2017). Effects of targeted therapies on the bone in arthritides. Autoimmun. Rev. 16, 313-320. doi: 10.1016/j.autrev.2017.01.014

Wang, N., Huang, X., Wang, X., Zhang, Y., Wu, R., and Shou, D. (2015). Pipette tip solid-phase extraction and high-performance liquid chromatography for the determination of flavonoids from Epimedii herba in rat serum and application of the technique to pharmacokinetic studies. J. Chromatogr. B 990, 64-72. doi: 10.1016/j.jchromb.2015.03.012

Xiao, H. H., Fung, C. Y., Mok, S. K., Wong, K. C., Ho, M. X., Wang, X. L., et al (2014). Flavonoids from Herba epimedii selectively activate estrogen receptor alpha (ER) and stimulate ER-dependent osteoblastic functions in UMR-106 cells. J. Steroid Biochem. Mol. Biol. 143, 141-151. doi: 10.1016/j.jsbmb.2014.02. 019

Xu, S., Zhang, Y., Liu, B., Li, K., Huang, B., Yan, B., et al. (2016). Activation of mTORC1 in B lymphocytes promotes osteoclast formation via regulation of 
b-Catenin and RANKL/OPG. J. Bone Miner. Res. 31, 1320-1333. doi: 10.1002/ jbmr. 2800

Yang, G., Yuan, G., Li, X., Liu, P., Chen, Z., and Fan, M. (2014). BMP-2 induction of Dlx3 expression is mediated by $\mathrm{p} 38 / \mathrm{Smad} 5$ signaling pathway in osteoblastic MC3T3-E1 cells. J. Cell. Physiol. 229, 943-954. doi: 10.1002/jcp.24525

Zhang, Y., Liang, R. J., Xu, J. J., Shen, L. F., Gao, J. Q., Wang, X. P., et al. (2017). Efficient induction of antimicrobial activity with vancomycin nanoparticleloaded poly (trimethylene carbonate) localized drug delivery system. Int. J. Nanomedicine 12, 1201-1214. doi: 10.2147/IJN.S127715

Zheng, D., Peng, S., Yang, S. H., Shao, Z. W., Yang, C., Feng, Y., et al. (2012). The beneficial effect of Icariin on bone is diminished in osteoprotegerin-deficient mice. Bone 51, 85-92. doi: 10.1016/j.bone.2012.04.006

Zhou, J., Chen, Y., Wang, Y., Gao, X., Qu, D., and Liu, C. (2013). A comparative study on the metabolism of Epimedium koreanum Nakai-prenylated flavonoids in rats by an intestinal enzyme (lactase phlorizinhydrolase) and intestinal flora. Molecules 19, 177-203. doi: 10.3390/molecules19010177

Conflict of Interest Statement: The authors declare that the research was conducted in the absence of any commercial or financial relationships that could be construed as a potential conflict of interest.

Copyright (C) 2017 Zhang, Shen, Mao, Wang, Wang, Huang, Hu, Shou and Wen. This is an open-access article distributed under the terms of the Creative Commons Attribution License (CC BY). The use, distribution or reproduction in other forums is permitted, provided the original author(s) or licensor are credited and that the original publication in this journal is cited, in accordance with accepted academic practice. No use, distribution or reproduction is permitted which does not comply with these terms. 